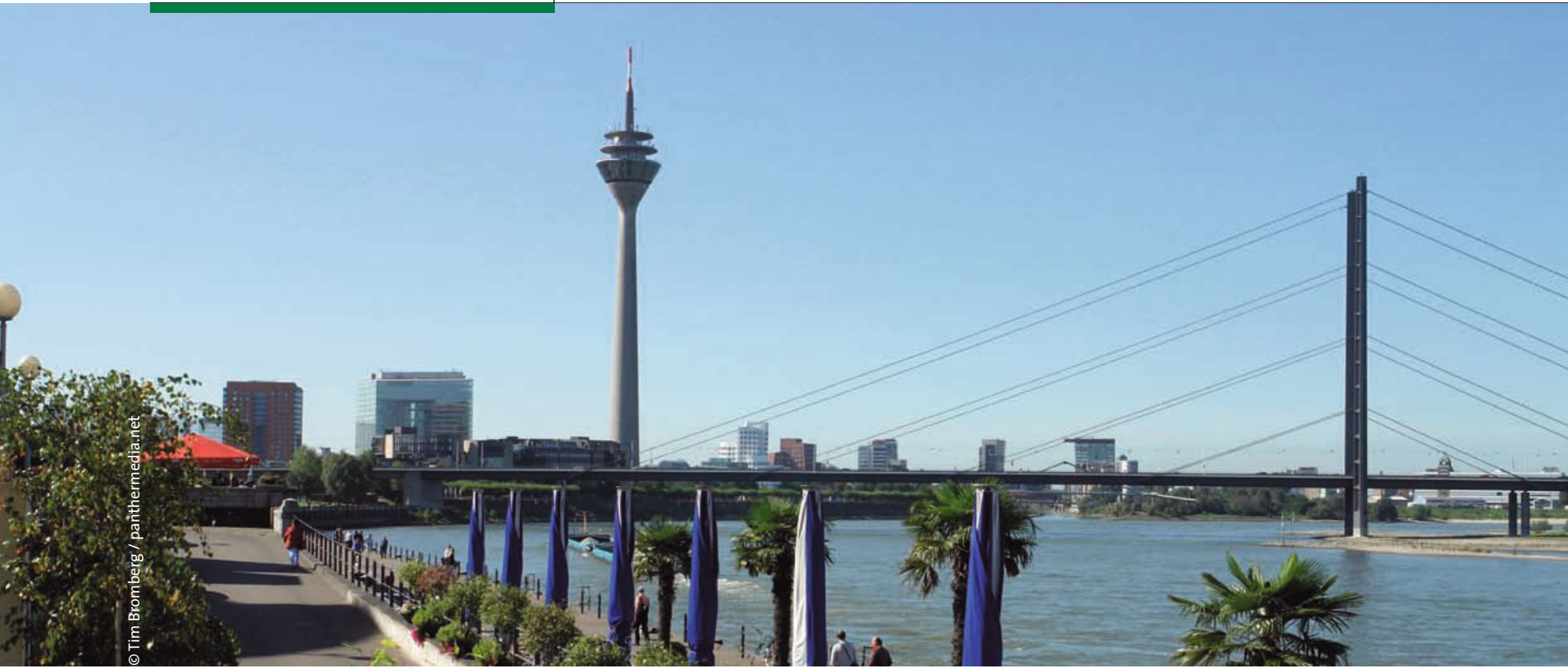

\title{
62. Kongress der Deutschen Gesellschaft für Urologie 2010
}

\begin{abstract}
Rund 6.800 Teilnehmer, davon 800 aus pflegenden Berufen, besuchten den diesjährigen Kongress der Deutschen Gesellschaft für Urologie (DGU) in Düsseldorf, der unter dem Motto „Forschung und Anwendung im Dialog“ stand. Ziel dieses translationalen Ansatzes ist, die wissenschaftlichen Erkenntnisse aus der klinischen und Grundlagenforschung möglichst schnell den Patienten zugute kommen zu lassen.
\end{abstract}

\section{Roboter-assistierte radikale Prostatektomie: erektile Funktion postoperativ erhalten}

— Mit der minimal-invasviven roboterassistierten radikalen Prostatektomie (RARP) ist ein Nerverhalt gut möglich, sodass die erektile Funktion in den meisten Fällen erhalten werden kann. Dr. Vahudin Zugor, Gronau, stellte dazu eigene Daten vor. Insgesamt wurden 600 RARPPatienten mit dem IIEF-5-Fragebogen zu ihren postoperativen Sexualfunktionen befragt mit einem Follow-up-Schema von 3, 6, 12, 24, 48 und 60 Monaten. Postoperativ erhielten die Patienten zweimal wöchentlich $5 \mathrm{mg}$ Tadalafil.

Der mittlere IIEF-5-Wert betrug postoperativ im Gesamtkollektiv 15,21, nach sechs Monaten 7,59 und zwölf Monate postoperativ 9,61. Mit einer nerverhaltenden Operation waren die Ergebnisse wesentlich besser: Bei einseitiger Nervschonung betrug der IIEF-5Wert nach sechs Monaten 13,45 und nach zwölf Monaten 15,22, bei beidseitiger Nervschonung entsprechend 15,39 beziehungsweise 17,99. In einer Subgruppe von Patienten < 60 Jahre konnte sogar ein Wert von 20,18 erreicht werden.

„Vor allem bei jüngeren Patienten ohne Komorbiditäten lässt sich bei günstiger onkologischer Situation mit beid- seitig möglichem Nerverhalt die erektile Funktion in den meisten Fällen erhalten“, erklärte Zugor. Neben Alter und Komorbiditäten des Patienten seien die Erfahrung des Operateurs, die verwendete Technik sowie die Ausbreitung des Tumors für den Therapieerfolg entscheidend. Vugor empfiehlt daher, sofern es die Tumorsituation gestattet, die radikale Prostatektomie zumindest einseitig nerverhaltend durchzuführen. $\quad$ slx

P 12 „Andrologie: Sexuelle Dysfunktion?” 